\title{
Historical and contemporaneous human-mediated processes left a strong genetic signature on honey bee populations from the Macaronesian archipelago of the Azores
}

\author{
Helena Ferreira ${ }^{1}$, Dora Henriques ${ }^{1}$, Cátia J. Neves ${ }^{1}$, Clycie A. S. Machado ${ }^{2}$, \\ João C. Azevedo ${ }^{1}$, Tiago M. Francoy ${ }^{3}$, M. Alice Pinto ${ }^{1}$ \\ ${ }^{1}$ Centro de Investigação de Montanha (CIMO), Instituto Politécnico de Bragança, Campus de Sta. Apolónia, 5300-253, \\ Bragança, Portugal \\ ${ }^{2}$ Faculdade de Filosofia, Ciências e Letras de Ribeirão Preto, Universidade de São Paulo, Av Bandeirantes, 3900, \\ Ribeirão Preto, SP 14040-900, Brasil \\ ${ }^{3}$ Escola de Artes, Ciências e Humanidades, Universidade de São Paulo, Rua Arlindo Béttio, 1000, São Paulo, SP 03828- \\ 000, Brasil
}

Received 17 May 2019 - Revised 9 October 2019 - Accepted 7 November 2019

\begin{abstract}
In this study, honey bees from the Macaronesian archipelago of the Azores were extensively surveyed to unveil diversity patterns. A total of 638 colonies were analyzed over two time periods using mtDNA and wing geometric morphometrics. The genetic composition revealed to be heterogeneous and related to historical and contemporary human-mediated introductions. The close relationship of Azorean populations with those from northern Portugal supports historical introductions by Portuguese settlers. The African sublineage $\mathrm{A}_{\text {III }}$ prevailed on five islands, contrasting with three islands where C haplotypes were dominant. On Pico and Graciosa, C haplotypes are due to recent imports of commercial queens. On Faial, the sudden replacement of $\mathrm{A}_{\mathrm{III}}$ by $\mathrm{C}$ haplotypes coincided with arrival of Varroa destructor. This study deepens the current understanding of Macaronesian honey bees, suggesting that they are variants of the Iberian honey bee with differential levels of Cderived introgression.
\end{abstract}

Iberian honey bee / tRNA ${ }^{\text {leu }}$-cox2 intergenic region / wing geometric morphometrics / DraI test

\section{INTRODUCTION}

The Western honey bee, Apis mellifera L., is native to Africa, Europe, Middle East, and some regions in Asia (Ruttner 1988). In this

Electronic supplementary material The online version of this article (https://doi.org/10.1007/s13592-019-00720-w) contains supplementary material, which is available to authorized users.

Corresponding author: M. Pinto, apinto@ipb.ptA. Pinto, apinto@ipb.pt

Handling editor: Klaus Hartfelder geographically broad and ecologically diverse area, the honey bee has differentiated into numerous subspecies (Ruttner 1988) assigned to four morphological or five mitochondrial lineages: A, M, C, O, and Y (Franck et al. 2001; Ruttner 1988). Based on mitochondrial variation of the $\mathrm{RNA}^{\text {leu }}$ cox2 intergenic region, the African lineage has been further divided into sublineages $\mathrm{A}_{\mathrm{I}}, \mathrm{A}_{\mathrm{II}}, \mathrm{A}_{\mathrm{III}}$, and $Z$ (Alburaki et al. 2011; Franck et al. 2001).

Islands have served as an important stage for honey bee diversification, harboring five subspecies. Four of them have evolved in Mediterranean islands (A. m. siciliana in Sicily, A. m. ruttneri in 
Malta, A. m. cypria in Cyprus, and A. m. adami in Crete) and one in Madagascar (A. m. unicolor), over long periods of isolation and adaptation to local environments (Ruttner 1988; Sheppard et al. 1997). While honey bees have also colonized islands of the Atlantic Ocean, such as Macaronesian islands, none of the surveyed populations have differentiated to the point of earning the subspecies status. Populations of the Macaronesian archipelagos, particularly those of the Canaries and, to a lesser extent, those of Madeira, the Azores, and Cape Verde, have been surveyed for morphology, mtDNA, and microsatellite variation (Álvarez et al. 2001; Álvarez et al. 1997; De la Rúa et al. 2001; De la Rúa et al. 1998; Franck et al. 2001; Miguel et al. 2015; Muñoz et al. 2013).

Morphological analyses revealed a closer resemblance of Canarian and Madeiran honey bees to southern Iberian than to northern African honey bees, which is consistent with historical humanmediated introductions from Iberia (Álvarez et al. 2001; Álvarez et al. 1997; Miguel et al. 2015). However, early mitochondrial surveys of the $\mathrm{Ca}$ narian populations detected a high frequency of $\mathrm{A}_{\text {III }}$ haplotypes, which, at the time, had not been reported to Spain (De la Rúa et al. 1998). This finding led to proposal of an African origin for the Canarian populations. This hypothesis was further supported by close microsatellite proximity between populations of Morocco and Madeira and the Azorean island of São Miguel (De la Rúa et al. 2006). Interestingly, maternal composition of these two Portuguese populations was somewhat distinct, despite low microsatellite differentiation. While haplotype A1 $\left(\mathrm{A}_{\mathrm{I}}\right)$ was ubiquitous on Madeira, similarly to the Canaries, it was absent on São Miguel (De la Rúa et al. 2006; De la Rúa et al. 1998; Muñoz et al. 2013). Furthermore, while $A_{\text {III }}$ haplotypes also prevailed on São Miguel, the most frequent haplotype was A14 instead of A15 (now A14', after a nomenclature revision by ChávezGalarza et al. 2017), as on the Canaries and Madeira. These incongruences claimed for a thorough population survey across the Azores to obtain a more complete picture of the diversity patterns of Macaronesian honey bees. Recent findings of a hotspot of $\mathrm{A}_{\text {III }}$ diversity in Atlantic populations of the Iberian honey bee (Chávez-
Galarza et al. 2017; Pinto et al. 2013) will provide an appropriate framework for interpreting the data generated by the survey of the Azorean populations.

The Iberian honey bee has been the subject of numerous surveys (Cánovas et al. 2008; ChávezGalarza et al. 2017, Chávez-Galarza et al. 2015; Miguel et al. 2011, Miguel et al. 2007; Pinto et al. 2013). Maternal markers revealed the existence of a sharp northeastern-southwestern cline formed by haplotypes of M- and A-lineage ancestry, and this pattern was recently supported by nuclear SNPs (Chávez-Galarza et al. 2015). Genetic structure was also observed in the African-derived populations occupying the southwestern half of Iberia. Along the Atlantic coast, $\mathrm{A}_{\mathrm{III}}$ haplotypes (including A14 and A14') prevailed in northern Portugal and northwestern Spain and these were completely replaced by $\mathrm{A}_{\mathrm{I}}$ haplotypes in southern Portugal. Haplotypes of $A_{I}$ ancestry were also predominant in southern Spain. However, while A2 was the most common $A_{I}$ haplotype in southern Spain, it was replaced by A1 in southern Portugal (Cánovas et al. 2008; Chávez-Galarza et al. 2017; Pinto et al. 2013).

The global movement of commercial queens and colonies, typically of C-lineage ancestry (A. m. ligustica, A. m. carnica, and buckfast), is threatening the genetic integrity of many populations across the honey bee native range, and Macaronesia is seemingly no exception (Muñoz et al. 2014b). While the African historical signature is still visible in the genomes of Macaronesian honey bees (Muñoz et al. 2013), it might be erased with continuing large-scale gene flow from $\mathrm{C}$-lineage colonies, as has occurred in some parts of $A$. $m$. siciliana native distribution (Muñoz et al. 2014a). The levels of C-lineage maternal introgression revealed to be high on $\mathrm{El}$ Hierro, La Gomera, Tenerife (Canary Islands), and São Miguel (Azores), and were negligible on La Palma, Gran Canaria (Canary Islands), and Madeira, reflecting differential beekeeping modes within the Spanish and Portuguese Macaronesian archipelagos (De la Rúa et al. 2006; Muñoz et al. 2013).

In an attempt to improve the honey bee genetic stock of the Azores, a breeding program was implemented in the 1980s. A. m. ligustica and 
A. m. caucasia queens were acquired to European breeders, reared on Santa Maria and Graciosa islands, respectively, and then crossed on Pico island. The rearing activities were accompanied by annihilation of hundreds of local colonies. Thousands of queens mated on Pico were then disseminated across the archipelago (Lhérété 1987). In addition to the breeding program, later on, there were imports of C-lineage queens (possibly A. m. ligustica and A. m. carnica) from mainland Europe and the New World.

Except for São Miguel island, where a large frequency of C-derived colonies has been reported (De la Rúa et al. 2006; Muñoz et al. 2013), the impact of the contemporary C-lineage introductions in the genetic composition of the remaining Azorean islands is unknown. To fill this gap, we conducted a survey across the Azores using wing geometric morphometrics and PCR-RFLPs of the tRNA ${ }^{\text {leu }}$-cox 2 mitochondrial region. We analyzed 638 colonies sampled in two distinct periods from 320 apiaries distributed across the Azores, and compared them with colonies from Iberia and other Macaronesian islands to address the following questions: (i) Is the genetic composition of the Azorean islands homogeneous? (ii) Did the maternal composition change over time? (iii) What is the impact of C-lineage introductions in the Azorean gene pool? (iv) How genetically close are the Azorean populations to the other Macaronesian and Portuguese mainland populations? And, (v) how concordant are the patterns of morphological and mitochondrial variation?

\section{MATERIALS AND METHODS}

\subsection{Sampling}

Between 2009 and 2011, a total of 164 samples, each representing a single colony and apiary, were collected from across the Azores archipelago (Figure S1). All the islands were re-sampled in the summer of 2014 and 2015. In this second survey, 474 colonies were collected from 156 apiaries, with the islands harboring a greater population size having a larger sample size (Table S1). Most apiaries were represented by three colonies. Workers were collected from the inner frames of the hives and were placed in absolute ethanol. Samples were stored at $-20{ }^{\circ} \mathrm{C}$ until analyses.

\subsection{DNA extraction and mitochondrial DNA analysis}

Total DNA was extracted from one leg of the 164 workers of the first survey using a $10 \%$ Chelex® protocol (Walsh et al. 1991) and from the thorax of the 474 workers of the second survey using the Ron's Tissue Mini Kit of BIORON®. The analysis of the mitochondrial DNA (mtDNA) consisted in the PCR-RFLP of the tRNA ${ }^{\text {leu }}$-cox2 intergenic region, known as the Dra I test (Garnery et al. 1993). The intergenic region was amplified with the primers E2 and H2 (Garnery et al. 1992), following the protocol described by Garnery et al. (1993) with slight modifications. The PCR products were digested with the Dra I restriction endonuclease, and the fragment sizes were determined on a $4 \%$ wide-range agarose gel. Haplotypes were identified and named following the nomenclature revision proposed by Rortais et al. (2011) and Chávez-Galarza et al. (2017). A random subset exhibiting $\mathrm{C}$-lineage and novel band patterns was Sanger-sequenced with primers E2 and H2. Sequences were checked for base calling and aligned with sequences from GenBank using MEGA 6.06 (Tamura et al. 2013).

Diversity measures, including mean number of haplotypes per locus $(\mathrm{Na})$, effective number of haplotypes $(\mathrm{Ne})$, number of private haplotypes $(\mathrm{Np}$ ), and unbiased diversity (uh), were obtained with GenAlEx 6.5 (Peakall and Smouse 2012). Fisher's exact tests were implemented to assess for genic differentiation between the two temporal surveys using Genepop on the web (Raymond and Rousset 1995). Pairwise $F_{\text {ST }}$ values between populations of the Azores (2014-2015 survey), Madeira, Canaries and the reference subspecies $A . m$. iberiensis were estimated using Arlequin 3.5.2.2 (Excoffier and Lischer 2010), with departures from zero tested by 10,000 permutations. Haplotype frequencies of Madeira and Canaries were obtained from the 2006-2011 survey of Muñoz et al. (2013). Haplotypes of 711 genetically tested A. m. iberiensis (Chávez-Galarza et al. 2015) were obtained from Chávez-Galarza et al. (2017). A neighbor-joining (Saitou and Nei 
1987 ) dendrogram was constructed with the $F_{\mathrm{ST}}$ values using MEGA 6.06 (Tamura et al. 2013).

\subsection{Geometric morphometrics analysis}

The 2014-2015 colonies $(N=472)$ were analyzed for wing venation patterns. The right forewings of five workers per colony were photographed with a digital camera attached to a stereomicroscope. Wing images of 5 workers per colony representing $707 \mathrm{~A}$. m. iberiensis (Chávez-Galarza et al. 2015) and 38 C-lineage (11 A. m. ligustica, 15 A. m. carnica and 12 A. m. caucasia) from the Morphometric Bee Data Bank in Oberursel (Germany) were also examined for comparison. These subspecies are presumably the main source populations introduced into the Azores. To compare the wing shape between the specimens, 19 homologous landmarks were plotted across the vein intersections of 5998 wings using tpsDig v2.17 (Rohlf 2013). Specimens with missing landmarks were eliminated. To minimize measurement errors, the same person plotted all the landmarks following the order shown in Figure S2. The tps file containing the dataset was used as input in MorphoJ v1.06a (Klingenberg 2011). The Cartesian coordinates of the specimens were Procrustes aligned, and the data were analyzed using canonical variate analysis (CVA). The analyses were performed using the mean of the five wings per colony. MorphoJ was also used to calculate pairwise Procrustes distances between populations. Procrustes distances were used to construct a neighborjoining dendrogram of the morphological proximity using MEGA 6.06 (Tamura et al. 2013).

\section{RESULTS}

\subsection{Mitochondrial DNA}

The Dra I test performed on the 638 colonies revealed existence of 14 haplotypes of A-, M-, and C-lineage ancestry in the Azores (Table I, Figure 1). The majority of the colonies belonged to lineage A with sublineage $\mathrm{A}_{\mathrm{III}}$ being highly predominant across the eight islands. $\mathrm{C}$ haplotypes were common in both surveys, although they were absent in São Jorge and rare on Santa
Maria and Terceira. M-lineage haplotypes were the least frequent and were found only on Graciosa, Terceira, and São Miguel.

A total of eight $A_{\text {III }}$ haplotypes were detected, contrasting with only two from $A_{I I}$ and one from $A_{I}$ (Table I). Haplotypes of $A_{I I}$ ancestry were observed at low frequencies and only on São Miguel and Santa Maria. AI was registered for the first time in the Azores, although in a single apiary from Faial. Of the 11 African haplotypes, only A14 was observed in every island in both surveys, with the highest proportions detected on Terceira and the lowest on Pico. In contrast, A11, A30, A34, and A64' were only detected either on São Miguel or Santa Maria. Haplotype A64' $\left(\mathrm{A}_{\text {III }}\right)$, which is private to Santa Maria, is reported for the first time (GenBank accession number MN543658).

Within lineage C, haplotypes C1 (35), C2j (20), and C3b (13) were detected on São Miguel, Pico, Faial, Graciosa, and Flores, as revealed by sequence data produced from a subsample of the 2014-2015 survey (Table S2). However, we report the global frequency of lineage $\mathrm{C}$ because the band patterns of these haplotypes could not be distinguished in the gel. Pico and Graciosa harbored a large $\mathrm{C}$-lineage population in both surveys (Table I). On Faial, the frequency of C haplotypes was $23 \%$ in $2009-2011$ but increased up to $75 \%$ in 2014-2015. Within lineage M, there were only two haplotypes: M70 on São Miguel and M7 on Terceira and Graciosa. The haplotype composition did not change over time, except on Faial $(P$ value $=0.00039$; Fisher's exact test) and Terceira $(P$ value $=0.00175)$.

The population of São Miguel showed the highest values for every diversity measure in both surveys (Table I). In contrast, Terceira exhibited a very low uh (0.025) and only 1.026 haplotypes $(\mathrm{Ne})$ in 2014-2015, and these values were considerably lower than those obtained for Pico ( $\mathrm{uh}=0.242, \mathrm{Ne}=$ 1.312 ), which exhibited the lowest diversity measures in 2009-2011, even though C haplotypes could not be discriminated by the PCR-RFLP.

Pairwise $F_{\text {ST }}$ values (Table II) and the Neighbor-joining tree (Figure 2) supported a closer proximity of the Azorean populations to those of northern $\left(0.1098 \leq F_{\mathrm{ST}} \leq 0.4440\right)$ than of southern mainland Portugal $\left(0.2569 \leq F_{\mathrm{ST}} \leq\right.$ $0.6637)$ or Iberia $\left(0.1363 \leq F_{\mathrm{ST}} \leq 0.3805\right)$, a trend 
H. Ferreira et al.

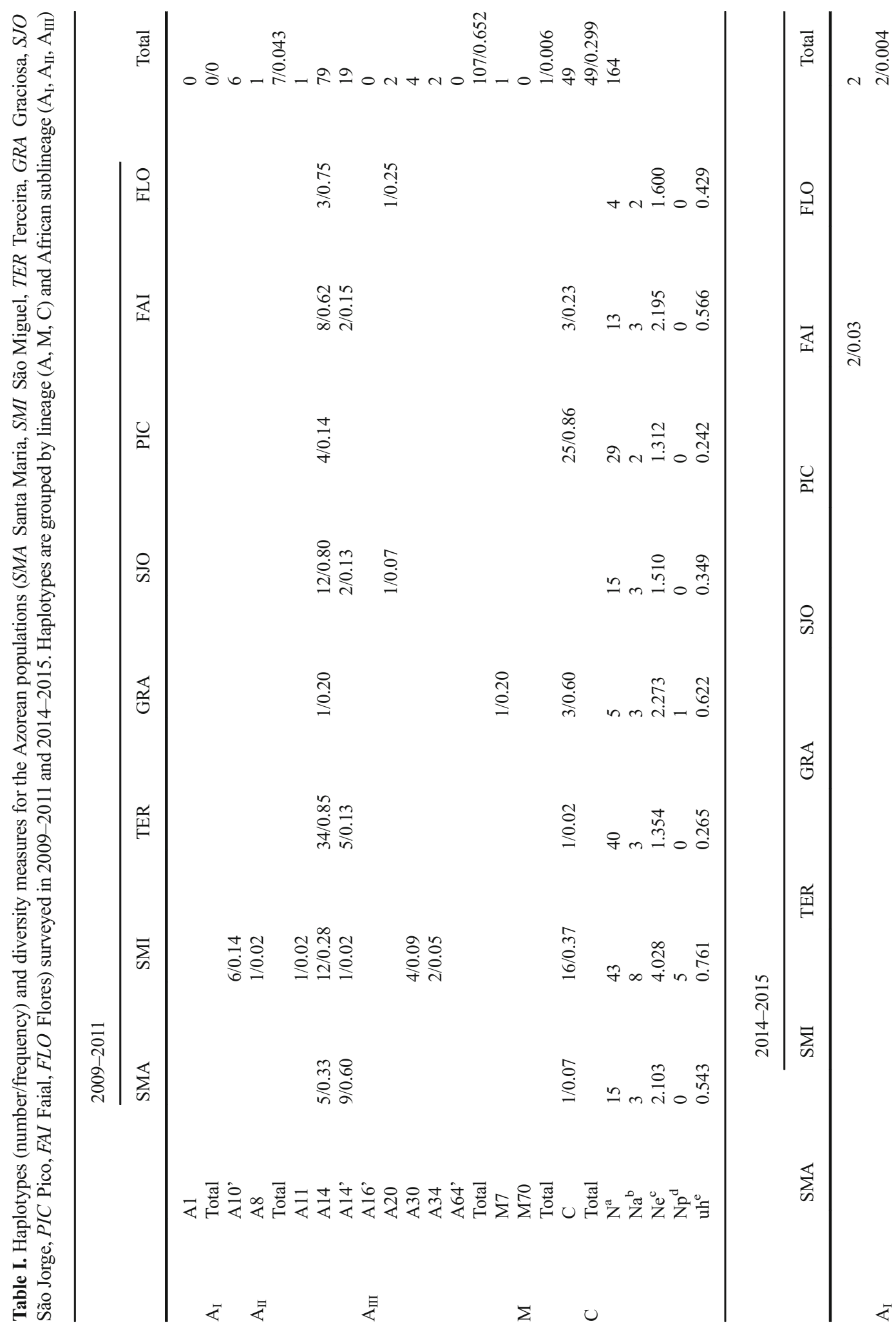


Genetic signature on Azorean honey bees

321

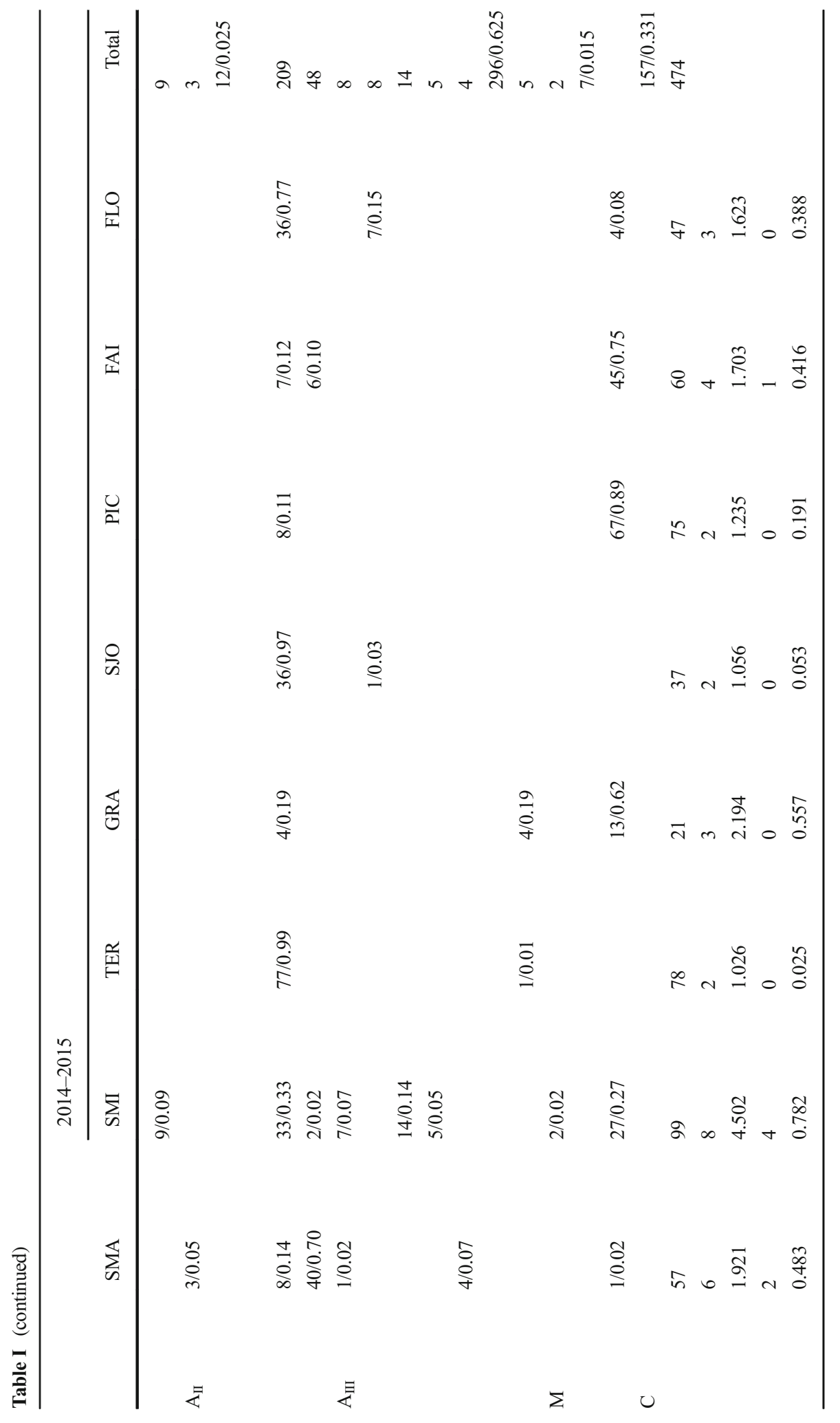

Springer 

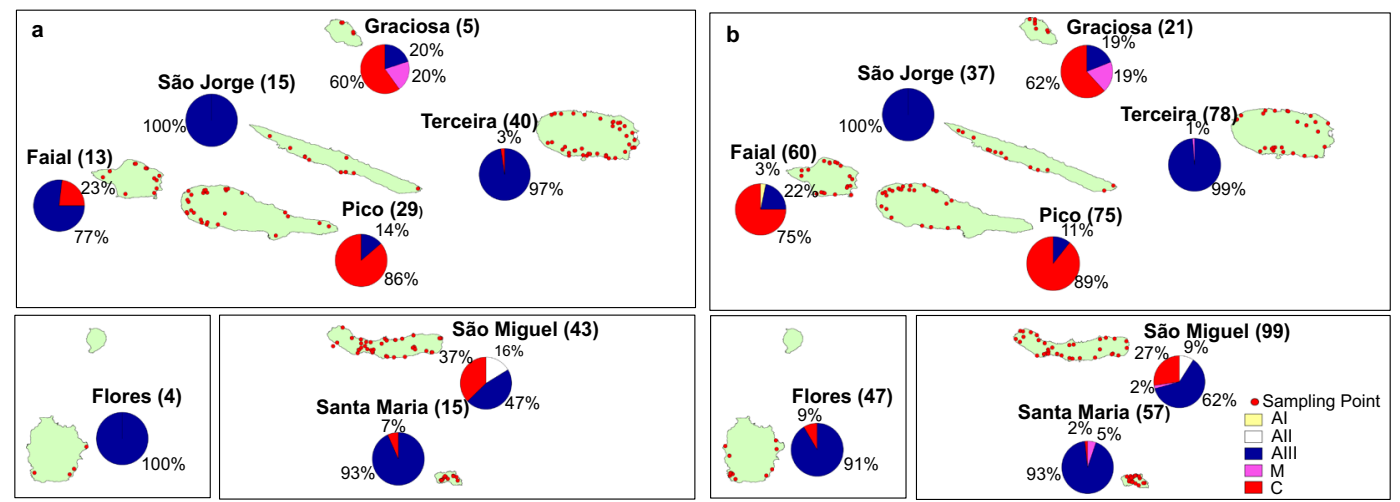

Figure 1. Maps showing the location of the apiaries (red dots) sampled in 2009-2011 (a) and 2014-2015 (b). The islands are displayed in accordance with the three geographical groups: oriental (Santa Maria, São Miguel), central (Terceira, Graciosa, Pico, São Jorge, Faial), and occidental (Flores). Sample sizes are shown within parenthesis. The pie charts display the distribution of the different lineages $(A, M$, and $C)$ and African sublineages $\left(A_{I}, A_{I I}, A_{I I I}\right)$.

that was paralleled by Madeiran and most Canarian islands. São Miguel $\left(F_{\mathrm{ST}}=0.1098\right)$, Graciosa $\left(F_{\mathrm{ST}}=0.2188\right)$, and Santa Maria $\left(F_{\mathrm{ST}}=0.2494\right)$ exhibited the highest genetic affinities with northern mainland Portugal, contrasting with Pico $\left(F_{\mathrm{ST}}\right.$ $=0.3973)$ and Terceira $\left(F_{\mathrm{ST}}=0.4440\right)$, which were the most distantly related. Interestingly, comparisons with the other Macaronesian archipelagos showed that, except for Santa Maria, all the Azorean islands are genetically closer to the Canaries than to mainland Portugal and Madeira. Within the Azores, the central group harbored both the least (Terceira and São Jorge: $F_{\mathrm{ST}}=$ $0.0060)$ and the most distantly related populations (Terceira and Pico: $F_{\mathrm{ST}}=0.8802$ ).

\subsection{Geometric morphometrics}

Canonical variate analysis suggested that the Azorean populations are morphologically closer to the Iberian honey bees than to the C-lineage subspecies (Figure 3). However, Graciosa stands out by sharing a greater similarity with the C-lineage $A . m$. ligustica and A. m. carnica and a higher distance to the O-lineage A. m. caucasia than any other Azorean populations (Figure 2B). Interestingly, although A. m. caucasia typically carries $\mathrm{C}$ haplotypes (Garnery et al. 1992), this subspecies is more distantly related to A. m. ligustica and A. m. carnica than to any Iberian or Azorean population (Table II). Apart from Graciosa, all Azorean populations exhibited lower Procrustes distance (PD) values with
A. m. iberiensis than with the other subspecies. Furthermore, the Azorean populations were more similar to those from northern Portugal $(0.0083<$ $\mathrm{PD}<0.0195)$ than southern Portugal or Iberia $(0.0105<\mathrm{PD}<0.0221,0.0101<\mathrm{PD}<0.0203)$. Within the Azores, Pico and Faial harbored the two closest populations $(\mathrm{PD}=0.0064)$, whereas Graciosa and Santa Maria harbored the two most distantly related $(\mathrm{PD}=0.0234)$.

\section{DISCUSSION}

Historical and anecdotal reports describe two important honey bee introduction events in the Azores archipelago. The first one dates back to the fifteenth century when the Portuguese colonized the islands, introducing honey bee colonies from mainland Portugal (Matos 1989). The second one occurred almost five centuries later in the framework of the breeding program approved by the regional government. Queens were acquired to breeders from France (allegedly A. m. caucasia from Georgia) and Italy (allegedly A. m. ligustica), reared on Graciosa and Santa Maria, crossed on Pico, and then disseminated across the Azores, particularly on São Miguel and Terceira (Lhérété 1987). In addition to the official breeding program, beekeepers continued importing (legally and illegally) queens of C-lineage ancestry from Europe and the New World (e.g., Canada and New Zealand). Unfortunately, one of the illegal occurrences led to the introduction of Varroa destructor on Pico in 2000. V. destructor 


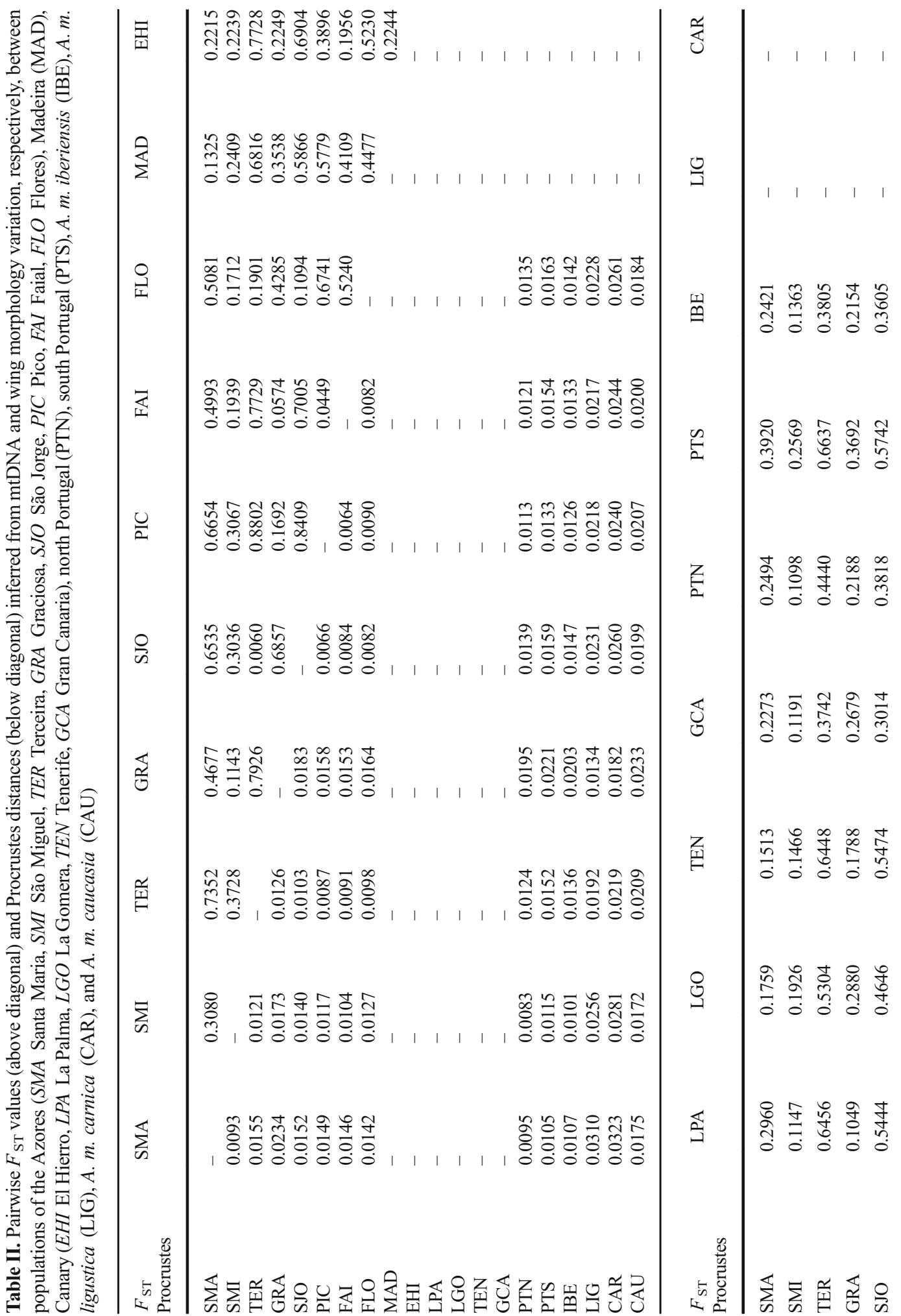


H. Ferreira et al.

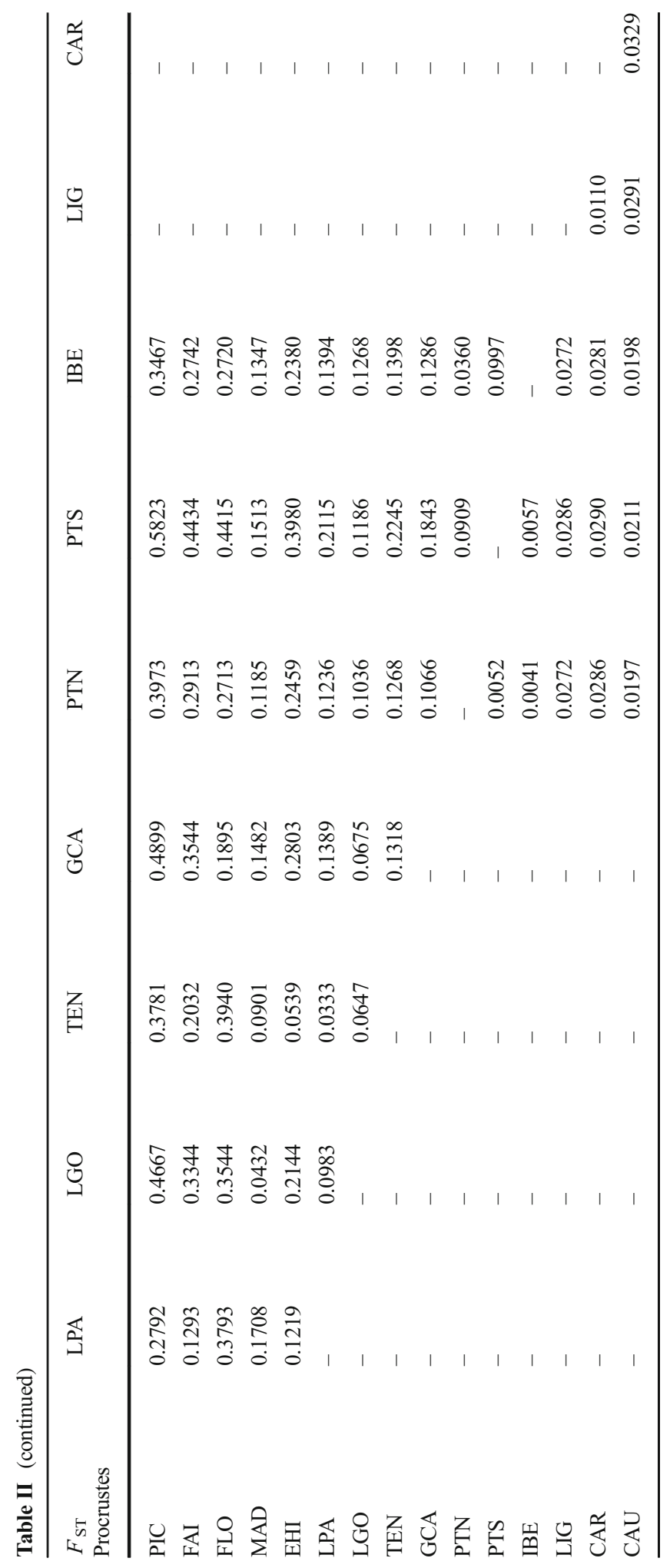



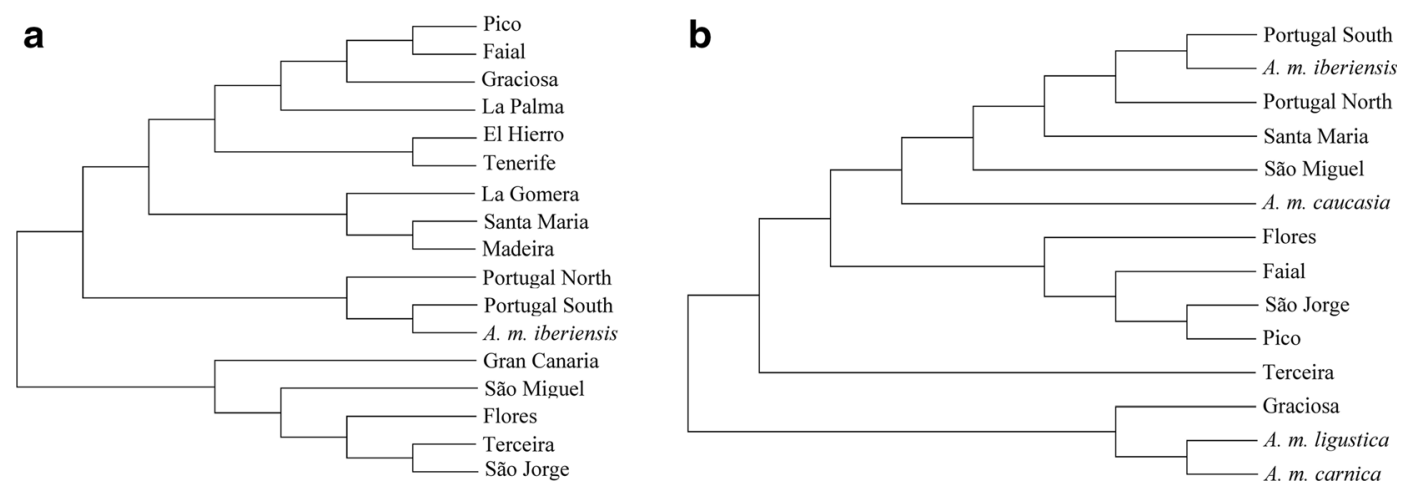

Figure 2. Neighbor-joining dendrogram of mtDNA (a) and morphological (b) proximity between populations of the Azores, north and south Portugal, and A. m. iberiensis, A. m. ligustica, A. m. carnica, and A. m. caucasia.

is now also present on Flores (since 2001) and Faial (since 2008).

Similarly to the Canaries (De la Rúa et al. 2001; De la Rúa et al. 1998; Muñoz et al. 2013), these human-mediated processes of mating and migration, possibly together with selection (natural and artificial) and drift, have shaped a heterogeneous gene pool in the Azores. Processes involving Clineage colonies have left a strong maternal signature in populations from Pico, Graciosa, Faial, and São Miguel, but not in populations from Terceira, São Jorge, and Santa Maria. However, maternal patterns have not always been paralleled by wing shape patterns. Pico and Faial harbor the highest levels of $\mathrm{C}$-lineage proportions in the last survey (89\% and 75\%, respectively), yet Procrustes distances inferred from wing shape data support a close proximity with São Jorge, the single Azorean island with undetected C-derived haplotypes through time. In Pico and Faial, either Cderived nuclear genes have been diluted through crosses with local drones or selected out. Alternatively, in São Jorge, populations were introgressed by C-derived drones introduced by beekeepers from the other islands of the central group before arrival of $V$. destructor, when trading among all the islands was allowed. If this is the case, absence of C-lineage matrilines in São Jorge could be explained by the action of genetic drift and/or selection.
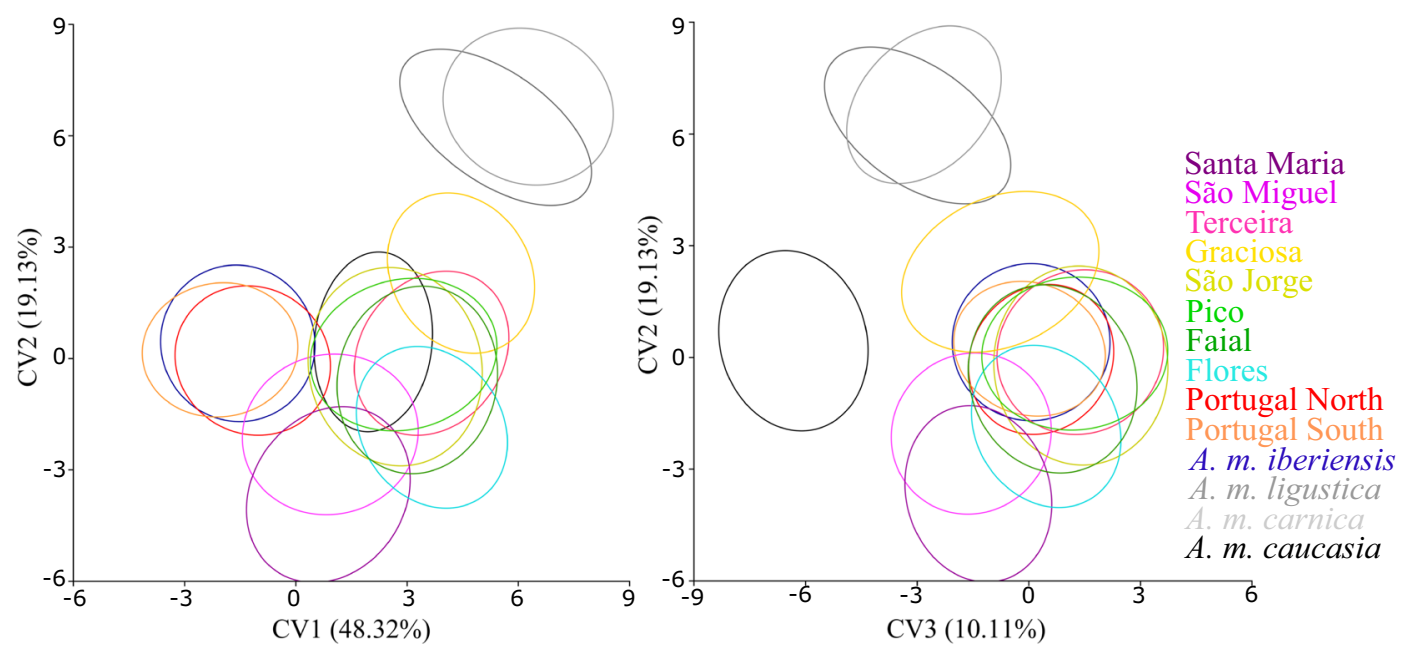

Figure 3. Scatterplots of individual scores from the canonical variant analysis of wing landmarks of populations from Azores, mainland Portugal, A. m. iberiensis, A. m. ligustica, A. m. carnica, and A. m. caucasia . 
Graciosa population also shows a consistently high proportion of $\mathrm{C}$ haplotypes (60\% and $62 \%$ ). However, contrarily to Pico and Faial, mtDNA patterns are congruent with morphometry data as Graciosa harbors the single population that clusters together with A. m. ligustica and A. m. carnica. Interestingly, in addition to $C$ haplotypes, Graciosa has the highest proportion of Mlineage sequences and all of them aligned with M7, a haplotype common in Italy (Franck et al. 2000) but rare elsewhere (Chávez-Galarza et al. 2017; Garnery et al. 1998; Jensen et al. 2005; Pinto et al. 2013). Altogether, these findings call into question alleged imports of $A$. m. caucasia queens from a French breeder (Lhérété 1987). Likely, queens introduced into Graciosa under the regional breeding program were of $\mathrm{C}$-lineage ancestry. Alternatively, A. m. caucasia genes were driven to extinction by selection or stochastic processes and replaced by $\mathrm{C}$-derived colonies due to subsequent unreported introductions.

After Pico, its geographically closest island, Faial, was home to the population with the highest frequency of C-derived haplotypes in the last survey. However, in the earlier survey, these haplotypes only accounted for $23 \%$ of the gene pool. The remarkable matriline turnover from a predominantly African (77\% in 2009-2011) to a predominantly C-derived population (75\% in 2014-2015) in such a short timeframe is likely linked to arrival of $V$. destructor in 2008. A turnover of similar scale coinciding with arrival of $V$. destructor has been reported in feral populations of Africanized honey bees, although in this case, European-derived haplotypes were replaced by African-derived haplotypes (Pinto et al. 2004). It is possible that $\mathrm{C}$-derived matrilines had a superior response to the invasive process, but most likely beekeepers brought in colonies from Pico, where there is a more active beekeeping community, to restock after the losses caused by $V$. destructor .

The two islands of the oriental group, Santa Maria and São Miguel, exhibited the closest wing shape proximity with $A$. $m$. iberiensis, despite the contrasting proportions of $C$ haplotype: lower than $2 \%$ on Santa Maria and above $27 \%$ on São Miguel. Contrary to São Miguel, Santa Maria exhibited congruent cytonuclear patterns with negligible signs of C-lineage introgression. This was an unexpected finding because Santa Maria worked as the stage for rearing A. $m$. ligustica during implementation of the breeding program (Lhérété 1987). São Miguel, despite the close proximity to A. $m$. iberiensis, at both mitochondrial and morphometric levels, still harbors a large proportion of C-derived haplotypes ( $27 \%$ in the 2014-2015 survey).

Similarly to the other Macaronesian archipelagos, the great majority of the African haplotypes in the Azores belong to sublineage $\mathrm{A}_{\text {III }}$, reflecting historical introductions of honey bees by Portuguese settlers (Miguel et al. 2015). However, contrarily to the other Macaronesian archipelagos, the most frequent $\mathrm{A}_{\text {III }}$ haplotype is A14, as opposed to A14' (De la Rúa et al. 2006; De la Rúa et al. 2001; De la Rúa et al. 1998; De la Rúa et al. 2002; Miguel et al. 2015; Muñoz et al. 2013). The single exception is Santa Maria, with 70\% of A14', explaining a closer genetic relationship with Madeira. A14 is the single haplotype that occurs on every Azorean island and one of the most widely distributed across the Canaries (De la Rúa et al. 2001; De la Rúa et al. 1998; Miguel et al. 2015; Muñoz et al. 2013), although its frequency is considerably higher in the Azores. Another major peculiarity of the Azorean honey bee populations is the virtual absence of A1, a common $A_{I}$ haplotype across the Canaries and Madeira (De la Rúa et al. 2001; De la Rúa et al. 1998; De la Rúa et al. 2002; Miguel et al. 2015; Muñoz et al. 2013). The close genetic relationship of the Azorean honey bees with those from Iberia, particularly from northern Portugal, further supports the hypothesis of a Portuguese origin for Macaronesian honey bees (Miguel et al. 2015).

This study, and the numerous accounts that have been published so far, suggests that honey bees inhabiting the Spanish and Portuguese Macaronesian archipelagos are variants of the Iberian honey bee A. m. iberiensis, with differential levels of C-derived introgression (De la Rúa et al. 2006; Miguel et al. 2015; Muñoz et al. 2013). Despite similarities, Azorean populations have differentiated from mainland populations possibly due to interacting evolutionary forces involving genetic drift, associated to the founder event that occurred during historical introductions, along with geographical isolation preventing gene flow, and adaptation to the insular conditions. Although $\mathrm{A}_{\text {III }}$ is the most frequently observed African sublineage in the Azores, the contemporary influence of beekeeping is reflected by the high 
proportions of C-lineage matrilines. Further investigation using nuclear markers such as single nucleotide polymorphisms is required to further advance the current knowledge about the history and demographics of the Azorean honey bees.

\section{ACKNOWLEDGMENTS}

We are indebted to numerous veterinarians and technicians of the Divisões de Intervenção Veterinária (Direcção Geral de Alimentação e Veterinária ), including Nuno Salvador, Janyne Sousa, Ivan castro, Alcino Silva, Célia Mesquita, Ana Jorge, José Dias, Paulo, Rico, Pedro Leal, Vagner Paulos, Luis Xavier, Luís Silva, Martins Silva, Carlos Gouveia, Ana Carina Coimbra, João Ramos, João Arruda, Edgardo Melo, João Luís, and Moniz da Ponte. Especially thanks are due to Paula Vieira and Frank Aguiar, who kindly coordinated and help collecting all the samples across islands. Claudineia Costa helped with MorphoJ.

\section{AUTHOR CONTRIBUTIONS}

MAP designed the experiment. HF, DH, MAP, and CJN performed the mtDNA identification. HF performed wing morphometrics with assistance of CASM and TMF. All the population genetics analyses were performed by $\mathrm{HF}$ with assistance of $\mathrm{DH}$, CJN, CASM, and TMF. JCA assisted with sampling and GIS. MAP and HF wrote the manuscript. All the authors critically reviewed the manuscript for important intellectual content.

\section{FUNDING INFORMATION}

CASM was supported by Coordenação de Aperfeiçoamento de Pessoal de Nível Superior Brasil (CAPES) - Finance Code 001. Financial support was provided through the program COMPETE 2020 - POCI (Programa Operacional para a Competividade e Internacionalização) and by Portuguese funds through FCT (Fundação para a Ciência e a Tecnologia) in the framework of the project BeeHappy (POCI-01-0145-FEDER-029871).

\section{COMPLIANCE WITH ETHICAL STANDARDS}

Conflict of interest The authors declare that they have no conflict of interests.
Les processus historiques et contemporains à médiation humaine ont laissé une forte signature génétique sur les populations d'abeilles mellifères de l'archipel macaronésien des Açores.

Abeille mellifère ibérique / région intergénique tRNAleu-cox2 / morphométrie géométrique des ailes / test Dra I.

Historische und zeitgenössische, vom menschen beeinflusste Prozesse hinteließen starke genetische Signaturen bei den Honigbienenpopulationen vom Macaronesian-Archipel der Azoren.

Iberische Honigbienen/ tRNAleu-cox2 Intergenische Region/ Flügelmorphologie/ DraI-Test.

\section{REFERENCES}

Alburaki, M., Moulin, S., Legout, H., Alburaki, A., Garnery, L. (2011) Mitochondrial structure of Eastern honeybee populations from Syria, Lebanon and Iraq Apidologie 42:628

Álvarez, F. P., da Silva, M. V., Campano, F., Vaquero, E. J., Flores, J., Puerta, F. P., Bustos, M. (2001) Discriminación entre poblaciones de abejas (Apis mellifera L.) del sur de España, centro de Portugal y Madeira Archivos de Zootecnia 50:79-89

Álvarez, P. F., Fernández, H. R., López, J. R., Puerta, P. F., Serrano, F. J., Bustos, M. (1997) Estudio morfológico de las abejas melíferas del archipiélago canario (Gran Canaria, Tenerife, La Palma, Gomera) Archivos de Zootecnia 47:451-459

Cánovas, F., De la Rúa, P., Serrano, J., Galián, J. (2008) Geographical patterns of mitochondrial DNA variation in Apis mellifera iberiensis (Hymenoptera: Apidae) J Zool Syst Evol Res 46:24-30

Chávez-Galarza, J., Garnery, L., Henriques, D., Neves, C. J., Loucif-Ayad, W., Jonhston, J. S., Pinto, M. A. (2017) Mitochondrial DNA variation of Apis mellifera iberiensis: further insights from a large-scale study using sequence data of the tRNA leu-cox 2 intergenic region Apidologie 48:533-544

Chávez-Galarza, J., Henriques, D., Johnston, J. S., Carneiro, M., Rufino, J., Patton, J. C., Pinto, M. A. (2015) Revisiting the Iberian honey bee (Apis mellifera iberiensis ) contact zone: maternal and genome-wide nuclear variations provide support for secondary contact from historical refugia Mol Ecol 24:2973-2992

De La Rúa, P., Galián, J., Pedersen, B. V., Serrano, J. (2006) Molecular characterization and population structure of Apis mellifera from Madeira and the Azores Apidologie 37:699-708 
De la Rúa, P., Galián, J., Serrano, J., Moritz, R. (2001) Genetic structure and distinctness of Apis mellifera L. populations from the Canary Islands Mol Ecol 10:1733-1742

De la Rúa, P., Serrano, J., Galián, J. (1998) Mitochondrial DNA variability in the Canary Islands honeybees (Apis mellifera L) Mol Ecol 7:1543-1547

De La Rúa, P., Serrano, J., Galián, J. (2002) Biodiversity of Apis mellifera populations from Tenerife (Canary Islands) and hybridisation with East European races Biodiversity \& Conservation 11:59-67

Excoffier, L., Lischer, H. E. (2010) Arlequin suite ver 3.5: a new series of programs to perform population genetics analyses under Linux and Windows Mol Ecol Resour 10:564-567

Franck, P., Garnery, L., Celebrano, G., Solignac, M., Cornuet, J. M. (2000) Hybrid origins of honeybees from Italy (Apis mellifera ligustica) and Sicily (A. m. sicula ) Mol Ecol 9:907-921

Franck, P., Garnery, L., Loiseau, A., Oldroyd, B., Hepburn, H., Solignac, M., Cornuet, J. M. (2001) Genetic diversity of the honeybee in Africa: microsatellite and mitochondrial data Heredity 86:420-430

Garnery, L., Cornuet, J. M., Solignac, M. (1992) Evolutionary history of the honey bee Apis mellifera inferred from mitochondrial DNA analysis Mol Ecol 1:145-154

Garnery, L., Franck, P., Baudry, E., Vautrin, D., Cornuet, J.M., Solignac, M. (1998) Genetic diversity of the west European honey bee (Apis mellifera mellifera and A. $\mathrm{m}$. iberica ) I. Mitochondrial DNA Genet Sel Evol 30:S31

Garnery, L., Solignac, M., Celebrano, G., Cornuet, J.-M. (1993) A simple test using restricted PCR-amplified mitochondrial DNA to study the genetic structure of Apis mellifera L Experientia 49:1016-1021

Jensen, A. B., Palmer, K. A., Boomsma, J. J., Pedersen, B. V. (2005) Varying degrees of Apis mellifera ligustica introgression in protected populations of the black honeybee, Apis mellifera mellifera, in northwest Eur Mol Ecol 14:93-106

Klingenberg, C. P. (2011) MorphoJ: an integrated software package for geometric morphometrics Mol Ecol Resour 11:353-357

Lhérété, J.-P. (1987) Missão técnica-Apicultura Technical Report

Matos, A. T. (1989) Povoamento e colonização dos Açores Portugal no Mundo 12:185-188

Miguel, I., Baylac, M., Iriondo, M., Manzano, C., Garnery, L., Estonba, A. (2011) Both geometric morphometric and microsatellite data consistently support the differentiation of the Apis mellifera M evolutionary branch Apidologie 42:150-161

Miguel, I., Garnery, L., Iriondo, M., Baylac, M., Manzano, C., Steve Sheppard, W., Estonba, A. (2015) Origin, evolution and conservation of the honey bees from La Palma Island (Canary Islands): molecular and morphological data J Apic Res 54:427-440

Miguel, I., Iriondo, M., Garnery, L., Sheppard, W. S., Estonba, A. (2007) Gene flow within the M evolutionary lineage of Apis mellifera: role of the Pyrenees, isolation by distance and post-glacial recolonization routes in the western Eur Apidologie 38:141-155

Muñoz, I., Dall' Olio, R., Lodesani, M., De la Rúa, P. (2014a) Estimating introgression in Apis mellifera siciliana populations: are the conservation islands really effective? Insect Conserv Divers 7:563-571

Muñoz, I., Pinto, M. A., De la Rúa, P. (2013) Temporal changes in mitochondrial diversity highlights contrasting population events in Macaronesian honey bees Apidologie 44:295-305

Muñoz, I., Pinto, M. A., De la Rúa, P. (2014b) Effects of queen importation on the genetic diversity of Macaronesian island honey bee populations (Apis mellifera Linneaus 1758) J Apic Res 53:296-302

Peakall, R., Smouse, P. E. (2012) GenAlEx 6.5: genetic analysis in Excel. Population genetic software for teaching and research-an update Bioinformatics 28:2537-2539 doi:https://doi.org/10.1093 /bioinformatics/bts460

Pinto, M. A., Henriques, D., Neto, M., Guedes, H., Muñoz, I., Azevedo, J. C., de la Rúa, P. (2013) Maternal diversity patterns of Ibero-Atlantic populations reveal further complexity of Iberian honeybees Apidologie 44:430-439 doi:https://doi.org/10.1007/s13592-013-0192-y

Pinto, M. A., Rubink, W. L., Coulson, R. N., Patton, J. C., Johnston, J. S. (2004) Temporal pattern of Africanization in a feral honeybee population from Texas inferred from mitochondrial DNA Evolution 58:1047-1055

Raymond, M., Rousset, F. (1995) An exact test for population differentiation Evolution 49:1280-1283

Rohlf, F. J. (2013) TPSdig,v.2.17 State University

Rortais, A., Arnold, G., Alburaki, M., Legout, H., Garnery, L. (2011) Review of the DraI-COI-COII test for the conservation of the black honeybee (Apis mellifera mellifera) Conserv Genet Resour 3:383-391 doi:https://doi.org/10.1007/s12686-010-9351-x

Ruttner, F. (1988) Biogeography and taxonomy of honeybees Springer Verlag, Berlin.

Saitou, N., Nei, M. (1987) The neighbor-joining method: a new method for reconstructing phylogenetic trees Mol Biol Evol 4:406-425

Sheppard, W. S., Arias, M. C., Grech, A., Meixner, M. D. (1997) Apis mellifera ruttneri, a new honey bee subspecies from Malta Apidologie 28:287-293

Tamura, K., Stecher, G., Peterson, D., Filipski, A., Kumar, S. (2013) MEGA6: Molecular Evolutionary Genetics Analysis version 6.0 Mol Biol Evol 30:2725-2729 doi:https://doi.org/10.1093/molbev/mst197

Walsh, P. S., Metzger, D. A., Higuchi, R. (1991) Chelex 100 as a medium for simple extraction of DNA for PCR-based typing from forensic material Biotechniques 10:506-513

Publisher's note Springer Nature remains neutral with regard to jurisdictional claims in published maps and institutional affiliations. 